\title{
RISK OF SLEEP DISORDERS IN PATIENTS WITH DECOMPRESSION SICKNESS: A NATIONWIDE, POPULATION-BASED STUDY IN TAIWAN
}

\author{
Wei-Shih Tseng ${ }^{1,2}$, Wu-Chien Chien ${ }^{3,4,5}$, Chi-Hsiang Chung ${ }^{3,4,6}$, Yu-Ching Chou $^{4}$ \& Nian-Sheng Tzeng ${ }^{7,8}$ \\ ${ }^{1}$ Department of Diving and Hyperbaric Medicine, Armed Force Kaohsiung General Hospital, \\ Zuoying Branch, Taipei, Taiwan \\ ${ }^{2}$ Department of Neurology, Tri-Service General Hospital, National Defense Medical Center, Taipei, Taiwan \\ ${ }^{3}$ Department of Medical Research, Tri-Service General Hospital, National Defense Medical Center, Taipei, Taiwan \\ ${ }^{4}$ School of Public Health, National Defense Medical Center, Taipei, Taiwan \\ ${ }^{5}$ Graduate Institute of Life Sciences, National Defense Medical Center, Taipei, Taiwan \\ ${ }^{6}$ Taiwanese Injury Prevention and Safety Promotion Association, Taipei, Taiwan \\ ${ }^{7}$ Department of Psychiatry, Tri-Service General Hospital, School of Medicine, \\ National Defense Medical Center, Taipei, Taiwan \\ ${ }^{8}$ Student Counseling Center, National Defense Medical Center, Taipei, Taiwan
}

received: 11.6.2018;

revised: 18.10.2018;

accepted: 6.11 .2018

\section{SUMMARY}

Background: Decompression sickness (DCS) primarily manifests musculoskeletal pain, cutaneous manifestations, lymphatic symptoms, and neurological symptoms. DCS might affect the central nervous system and induce the stress in the patients, but few studies about the psychiatric morbidity after DCS have been conducted. This study aimed to investigate the association between DCS and the risk of developing psychiatric disorders.

Subjects and methods: This study was a population-based, matched-cohort design. A total of 738 enrolled patients, with 123 study subjects who had suffered from DCS, and 615 controls matched for sex and age, from the Longitudinal Health Insurance Databank from 2000-2010 in Taiwan, and selected from the National Health Insurance Research Database. After adjusting for the confounding factors, Cox proportional hazards analysis was used to compare the risk of developing psychiatric disorders during the 10 years of follow-up period.

Results: Of the study subjects, 10 (8.13\%) developed psychiatric disorders when compared to 35 (5.69\%) in the control group. The study subjects were more likely to develop psychiatric disorders (crude hazard ratio [HR]: 2.79 (95\% CI=1.37-5.69, $P<0.01$ ). After adjusting for sex, age, monthly income, urbanization level, geographic region, and comorbidities, the adjusted HR was 3.83 (95\% CI=1.60-9.16, $P<0.01)$. Sleep disorders was associated with DCS with the adjusted HR as 5.74 (95\% CI=1.04-31.56, $P<0.01)$. Hyperbaric oxygenation therapy was not associated with a lower risk of psychiatric disorders.

Conclusions: Patients who suffered from DCS have a 3.8-fold risk of developing psychiatric disorders, and a 5.7-fold risk of sleep disorders. This finding is a reminder for the clinicians that a regular psychiatric follow-up might well be needed for these patients.

Key words: decompression sickness - psychiatric disorders - sleep disorders - National Health Insurance Research Database Cohort study

\section{INTRODUCTION}

Decompression sickness (DCS) is a disease caused primarily by bubbles formed from the dissolved gas in the blood and/or tissue after an acute reduction in ambient pressure (Edmonds et al. 2015). DCS had traditionally been subdivided into type I and type II categories, and the manifestations of type II DCS are neurological, vestibular, and cardiopulmonary symptoms (Jain 2016). DCS might affect the central nervous system, but few studies about the psychiatric morbidity after DCS have been completed (Hopkins \& Weaver 2001, Nicolas et al. 2000). Therefore, the study for the risk of psychiatric disorders after DCS is, as yet, to be examined.

Intracerebral white matter lesions have been reported on magnetic resonance imaging (MRI) in divers, even without a history of DCS (Connolly \& Lee 2015). Nitrogen microbubbles may be responsible for these lesions and could lead to chronic neurological dysfunction (Kohshi et al. 2014). In addition to the direct influence on the central nervous system (CNS), there might well be an indirect impact on sleep quality due to the microbubbles and diving. A recent study concluded that diving, as a stress stimulant, induced higher cortisol levels (Pourhashemi et al. 2016), which could influence the diver's sleep quality (Vgontzas et al. 2003). DCS might affect the central nervous system, and the stress from diving itself and DCS could also influence the patients, but few studies about the psychiatric morbidity after DCS have been conducted (Hopkins \& Weaver 2001, Morgan 1995, Nicolas et al. 2000). Therefore, the study for the risk of psychiatric disorders after DCS is important and needed to be examined. 
The National Health Insurance (NHI) Program was launched in Taiwan in 1995, and as of June 2009, included contracts with $97 \%$ of the medical providers with approximately 23 million beneficiaries, or more than $99 \%$ of the entire population in Taiwan (Ho Chan 2010). Therefore, we used the National Health Insurance Research Database (NHIRD) to study the association between the DCS and the risk of sleep disorders. Therefore, we could utilize the National Health Insurance Research Database (NHIRD) to test the hypothesis that DCS is associated with the risk of psychiatric disorders.

\section{SUBJECTS AND METHODS}

\section{Data sources}

The present study used the NHIRD to identify inpatients with a discharge diagnosis of DCS, based on the International Classification of Diseases, $9^{\text {th }}$ Revision, Clinical Modification (ICD-9-CM) code (993.3) during 2000-2010. The NHIRD, which contains all claims data of the beneficiaries, uses ICD-9-CM codes to record diagnoses, and has the advantage in providing a largescale, longitudinal, reliable dataset, leading to extensive usages for population-based researches (Chen et al. 2010). It covers both the outpatient and inpatient services for approximately $99 \%$ of the entire 23 million population of Taiwan. In this study, we used outpatient and hospitalization data from the Longitudinal Health Insurance Database (LHID), a subset of the NHIRD, which contains $1,000,000$ original claims data which were randomly sampled from the 2005 registry of all the beneficiaries under the NHI program. Individuals with incomplete information in sex and age were excluded from the data analyses. The database would then review and remove the duplications of data from the technical or registration problems, since each insured individual is supposed to have only one entry of data in the NHI records.

\section{Study design and sampled participants}

This study was a population-based, matched-cohort design. Patients with newly diagnosed DCS were selected from the Inpatient Dataset from January 1, 2000, to December 31, 2010, according to a diagnosis of DCS (ICD-9-CM 993.3). All diagnoses of DCS were made by board-certified undersea and hyperbaric medicine physicians, according to the clinical, findings. Licensed medical records technicians verified the coding before claiming the reimbursements in hospitals and clinics. The NHI Bureau appoints several senior external specialists in undersea and hyperbaric medicine for randomly reviewing the records of ambulatory care visits and in-patient claims to verify the accuracy of the diagnoses. The patients with DCS before 2000 were excluded. In addition, the patients diagnosed with psychiatric disorders before the first visit for DCS were also excluded. All patients aged $<20$ years were also excluded.
The DCS patients were matched by using 1:5 sex, age, and index year-matched controls. The 1:5 match was used due to the statistical power achieved being 0.901 at this ratio, while the ratio was $1: 1$ to $1: 4$, the statistical power would have been lower than 0.9 (Figure 1). Type I DCS was defined by the symptoms involved skin, musculoskeletal or lymphatic system, and Type II DCS involved central nervous system, and the type II could be divided as mild and severe form of neurological DCS (Francis et al. 2003, Howle et al. 2017).

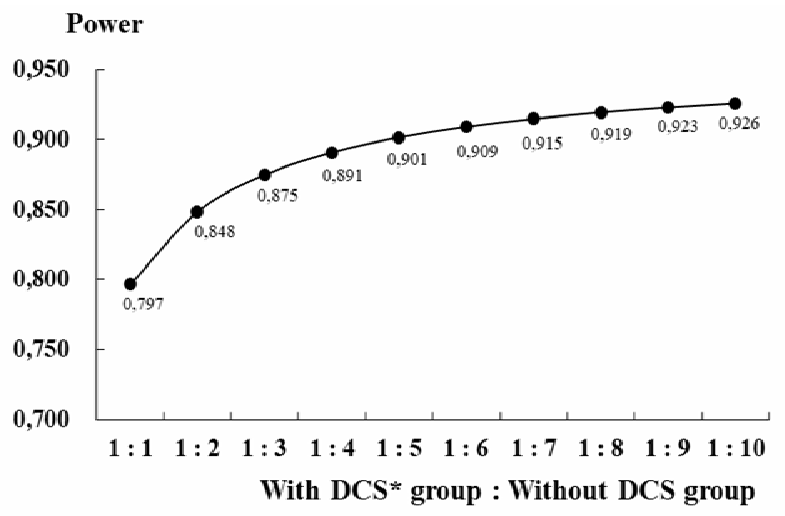

Figure 1. The statistical power of the different ratios of DCS* and the matching of non-DCS group (* DCS $=$ decompression sickness)

\section{Ethics}

Access of the NHIRD has been approved by the National Health Research Institutes (NHRI) Ethics Review Committee. The Institutional Review Board (IRB, the ethical committee) of Tri-Service General Hospital approved the research with waiving the need for individual written informed consent in such a study (IRB No. 1-104-05-145).

\section{Covariates}

The covariates are demographic factors that included sex, age group (20-44, 45-64, $\geq 65$ years), geographical area of residence (north, center, south, and east of Taiwan), urbanization level of residence, seasons, levels of care, occupational injury, and monthly income (Table 1). One study in Mexico has reported that the age range was as wide as 20 to 59 years in the patients with DCS (Huchim-Lara et al. 2017), therefore, we used the age groups as above to analyze the effects of different age groups. The usage of the hyperbaric oxygen (HBO) therapy for either group was also recorded.

\section{Comorbidity}

Pre-defined comorbidities included diabetes mellitus (ICD-9-CM 250), hypertension (ICD-9-CM 401.1, 401.9, 402.10, 402.90, 404.10, 404.90, 405.1, 405.9), hyperlipidaemia (ICD-9-CM 272.x), coronary artery disease (CAD, ICD-9-CM code 410-414), and obesity (ICD-9-CM 278). 
Table 1. Demographic factors enrollees in this study

\begin{tabular}{|c|c|}
\hline Covariates & Descriptions \\
\hline Sex & female vs male \\
\hline Age groups & $20-44,45-64, \geq 65$ years \\
\hline \multicolumn{2}{|c|}{ Urbanization level of residence* } \\
\hline Level 1 & $\begin{array}{l}\text { Population: }>1,250,000 \text {, with a } \\
\text { specific designation as political, } \\
\text { economic, cultural, and } \\
\text { metropolitan development }\end{array}$ \\
\hline Level 2 & $\begin{array}{l}\text { Population: } 500,000-1,249,999, \\
\text { playing an important role in the } \\
\text { politics, economy, and culture }\end{array}$ \\
\hline Level 3 & Population: 149,999-499,999, \\
\hline Level 4 & Population: $<149,999$ \\
\hline Seasons & Spring, summer, autumn, and winter \\
\hline Levels of care & $\begin{array}{l}\text { Medical centers, regional } \\
\text { hospitals, and local hospitals }\end{array}$ \\
\hline Occupational injury** & * Gave kind 1 and 2 \\
\hline \multicolumn{2}{|l|}{ Monthly incomes } \\
\hline & $\geq 35,000 \mathrm{NT} \$$ \\
\hline & $18,000-34,999$ NT\$ \\
\hline & $<18,000 \mathrm{NT} \$$ \\
\hline \multicolumn{2}{|c|}{$\begin{array}{l}\text { DCS= Decompression sickness; NT } \$=\text { New Taiwan Dollars; } \\
\text { *Defined according to the population and various indicators of } \\
\text { the level of development; ** In the National Health Insurance } \\
\text { Research Database, a column named "Gave Kind" indicated } \\
\text { different types of conditions, including: " } 1 \text { " for occupational } \\
\text { injury, "2" for occupational disease, " } 3 \text { " for non-occupational } \\
\text { injury, and "4" for non-occupational disease }\end{array}$} \\
\hline
\end{tabular}

\section{Outcome measures}

All of the study participants were followed from the index date until the onset of a depressive disorders (ICD-9-CM 296.2-296.3, 300.4, 311), anxiety disorders (ICD-9-CM 300.0, 300.2-300.3, 300.9), sleep disorders (excluding sleep apnoea, ICD-9-CM 307.4, 780.5), stress-related disorders (adjustment disorders, ICD-9-CM 309.0-309.4, 309.82-309.83, 309.89, 309.9; posttraumatic stress disorders, PTSD, ICD-9-CM 309.81; acute stress disorder, ASD, ICD-9-CM 308; acute and reactive psychosis, ICD-9-CM 298), delirium (ICD-9-CM 293), dementia and other cognitive disorders (ICD-9-CM 290, 294), withdrawal from the NHI program, or the end of 2010.

\section{Statistical analysis}

All statistical analyses were performed using the SPSS for Windows, version 22.0 (IBM Corp., Armonk, $\mathrm{NY}) \chi^{2}$ and $\mathrm{t}$ tests were used to evaluate the distributions of the categorical and continuous variables, respectively, with Fisher's exact examination. Cox proportional hazards analysis was used to determine the risk of psychiatric disorder. The results were presented as hazard ratio (HR) with a 95\% confidence interval (CI). Differences in the risk of psychiatric disorders between the study and control groups were estimated using the Kaplan-Meier method with the log-rank test. A 2-tailed $p$ value $<0.05$ was considered to indicate statistical significance and the uncertain possibility of type II errors.

\section{RESULTS}

In the dataset of the LHID, 182 individuals with DCS were found. Those with DCS diagnosed before 2000, psychiatric disorders before the first visit for DCS, unknown sex, or aged $<20$ were excluded. Therefore, a total of 738 patients were enrolled, including 123 subjects with DCS and 615 controls without DCS (Table 2). Among the 182 individuals with DCS, 59 were excluded for diagnosis with DCS before 2000, with psychiatric disorders before the tracking, with unknown, or of age $<20$ (Figure 2). Table 2 shows the distributions of the demographic characteristics and medical comorbidities among patients with and without DCS in Taiwan. As expected from our matching methodology, there were no significant differences in sex and age. A comparison with controls revealed that the patients with DCS were less likely to have the comorbidities of diabetes mellitus $(4.1 \%$ vs $9.4 \%, \mathrm{P}=0.03)$, and coronary artery disease $(0.8 \%$ vs $4.9 \%, \mathrm{P}<0.01)$. When compared with the control subjects, the DCS cases showed significant associations with those residing in the south $(30.9 \%$ vs $29.1 \%)$, and east $(7.3 \%$ vs $3.7 \%)(\mathrm{P}<0.01)$, urbanization level $2(50.4 \%$ vs $40.2 \%)$, and level $4(39.9 \%$ vs $16.4 \%)(\mathrm{P}<0.01)$, local hospitals (48.8\% vs $35.5 \%, \mathrm{P}=0.009)$, HBO therapy (39.8\% vs $0.3 \%, \mathrm{P}<0.001)$, and occupational injury ( $4.1 \%$ vs $1.5 \%$ $\mathrm{P}=0.01$ ) (Table 2).

Within the follow-up period, $8.1 \%(n=10)$ of the patients were diagnosed with psychiatric disorders in the DCS group, and $35(5.7 \%)$ were diagnosed with psychiatric disorders in the control group. The study subjects had higher frequency in those aged 45-64 years than in the controls $(47.2 \%$ vs $36.8 \%, \mathrm{P}=0.01$, data not shown). Figure 3 shows the Kaplan-Meier analysis for the cumulative incidence of psychiatric disorders in the study and control groups. In addition, at the sixth year of follow-up, the difference of the cumulative incidences of psychiatric disorders between the two groups became significant (log rank test, $\mathrm{P}<0.01$ ). The difference of the cumulative incidences of psychiatric disorders was shown in Table 3 . Table 4 shows the results of the single and multi-variable analysis for the factors of psychiatric disorders. After adjusting for sex, comorbidities, season, urbanization level, level of care, HBO therapy, occupational injury, and insured premium, the Cox regression analysis showed that the adjusted HR for the case patients diagnosed with psychiatric disorders was 3.83 (95\% CI=1.60-9.16, $\mathrm{P}<0.01)$, when compared with the control group. In addition, patients aged 45-64 have a decreased risk of developing psychiatric disorders with the reference of the age group of 20-44 (HR=0.40; $95 \%$ CI 0.19 to $0.82 ; \mathrm{P}=0.01)$. Among these psychiatric disorders, only sleep disorders had a significant increased risk. (Table 5).

In the Table 6, the adjusted HRs of psychiatric and sleep disorders increased with the severity of DCS, and increased risk of psychiatric disorders, especially sleep 
Table 2. Characteristics of study at the baseline

\begin{tabular}{|c|c|c|c|c|c|}
\hline \multirow{2}{*}{$\begin{array}{l}\text { Decompression sickness } \\
\text { Variables }\end{array}$} & \multicolumn{2}{|c|}{ With } & \multicolumn{2}{|c|}{ Without } & \multirow{2}{*}{$\mathrm{P}$} \\
\hline & $\mathrm{n}$ & $\%$ & $\mathrm{n}$ & $\%$ & \\
\hline Total & 123 & 16.7 & 615 & 83.3 & \\
\hline Gender & & & & & 0.99 \\
\hline Male & 113 & 91.9 & 565 & 91.9 & \\
\hline Female & 10 & 8.1 & 50 & 81 & \\
\hline Age (years) & & & & & 0.99 \\
\hline $20-44$ & 67 & 54.5 & 335 & 54.5 & \\
\hline $45-64$ & 49 & 39.8 & 245 & 39.8 & \\
\hline$>65$ & 7 & 5.7 & 35 & 5.7 & \\
\hline \multicolumn{6}{|l|}{ Comorbidity } \\
\hline $\mathrm{DM}$ & 5 & 4.0 & 58 & 9.4 & $0.03 *$ \\
\hline Hypertension & 5 & 4.0 & 41 & 6.7 & 0.19 \\
\hline Hyperlipidaemia & 1 & 0.8 & 15 & 2.4 & 0.22 \\
\hline CAD & 1 & 0.8 & 30 & 4.9 & $<0.01 * *$ \\
\hline Obesity & 0 & 0 & 0 & 0 & - \\
\hline Season & & & & & $0.03 *$ \\
\hline Spring (March-May) & 36 & 29.3 & 167 & 27.2 & \\
\hline Summer (June-August) & 41 & 33.3 & 137 & 22.3 & \\
\hline Autumn (September-November) & 26 & 21.1 & 166 & 27.0 & \\
\hline Winter (December-Feburary) & 20 & 16.3 & 145 & 23.6 & \\
\hline Location & & & & & $<0.01 * *$ \\
\hline Northern Taiwan & 34 & 27.6 & 223 & 36.3 & \\
\hline Middle Taiwan & 7 & 5.7 & 186 & 30.2 & \\
\hline Southern Taiwan & 38 & 30.9 & 179 & 29.1 & \\
\hline Eastern Taiwan & 9 & 7.2 & 23 & 3.7 & \\
\hline Outlets islands & 35 & 28.5 & 4 & 0.7 & \\
\hline Urbanization level & & & & & $<0.01 * *$ \\
\hline 1 (The highest) & 11 & 8.9 & 205 & 33.3 & \\
\hline 2 & 62 & 50.4 & 247 & 40.2 & \\
\hline 3 & 1 & 0.8 & 62 & 10.1 & \\
\hline 4 (The lowest) & 49 & 39.8 & 101 & 16.4 & \\
\hline Level of care & & & & & $<0.01 * *$ \\
\hline Hospital center & 26 & 21.1 & 201 & 32.7 & \\
\hline Regional hospital & 37 & 30.1 & 196 & 31.9 & \\
\hline Local hospital & 60 & 48.8 & 218 & 35.5 & \\
\hline HBO therapy & 49 & 39.8 & 2 & 0.3 & $<0.01 * *$ \\
\hline Occupational injury & 5 & 4.1 & 9 & 1.5 & $0.01^{*}$ \\
\hline Insured premium (NT\$) & & & & & 0.24 \\
\hline$<18,000$ & 119 & 96.8 & 605 & 98.4 & \\
\hline $18,000-34,999$ & 4 & 3.3 & 8 & 1.3 & \\
\hline$>35,000$ & 0 & 0 & 2 & 0.3 & \\
\hline
\end{tabular}

$\mathrm{P}($ Chi-square/Fisher exact test $):{ }^{*} \mathrm{P}<0.05, * * \mathrm{P}<0.01 ; \quad$ DM: Diabetes mellitus; CAD: Coronary artery disease; HBO: Hyperbaric oxygenation therapy

Table 3. The cases of psychiatric disorders in the years after Decompression sickness

\begin{tabular}{lccc}
$\begin{array}{l}\text { Decompression sickness } \\
\text { Tracking years }\end{array}$ & With & Without & Psychiatric disorders (N) \\
\hline 1 & Psith & 0.668 \\
2 & 3 & 8 & 0.795 \\
3 & 3 & 13 & 0.844 \\
4 & 6 & 16 & 0.097 \\
5 & 8 & 18 & 0.151 \\
6 & 10 & 22 & 0.008 \\
7 & 10 & 26 & 0.018 \\
8 & 10 & 27 & 0.003 \\
9 & 10 & 30 & 0.009 \\
10 & 10 & 31 & 0.015 \\
11 & 10 & 33 & 0.003 \\
\hline
\end{tabular}




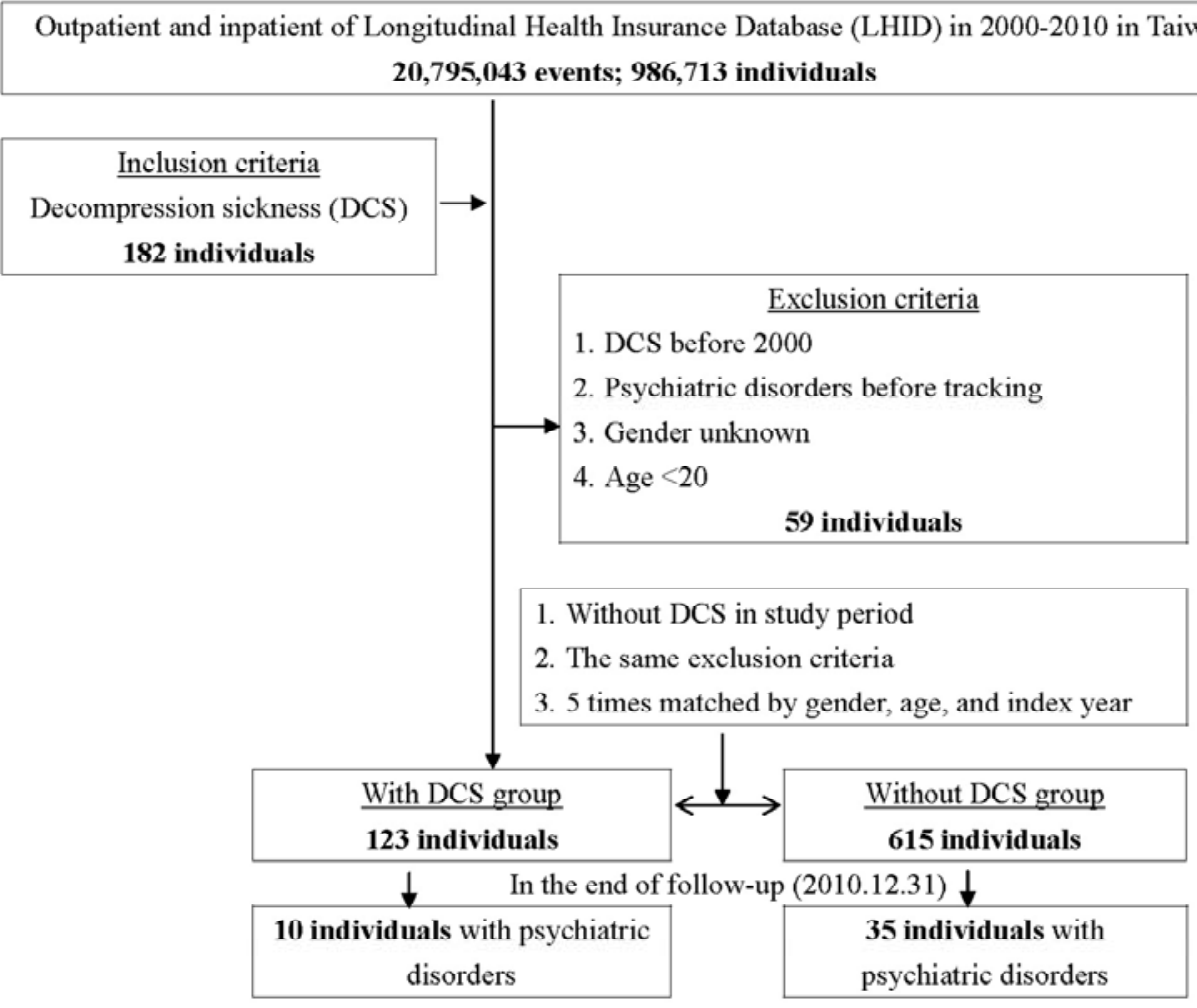

Figure 2. The flowchart of study sample selection from National Health Insurance Research Database in Taiwan

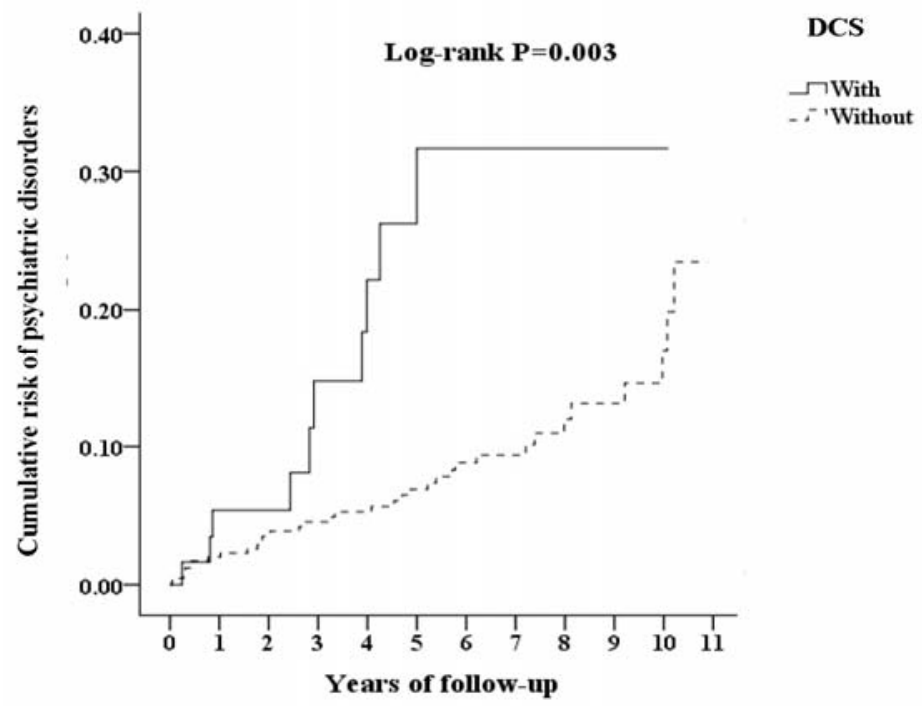

Figure 3. Cumulative risk of psychiatric disorders among aged 20 and over stratified by decompression sickness (DCS) with log-rank test

Table 4. Factors of psychiatric disorders by using Cox regression

\begin{tabular}{lcccccccc}
\hline Variables & Crude HR & $95 \%$ CI & $95 \%$ CI & P & Adjusted HR & $95 \%$ CI & $95 \%$ CI & P \\
\hline $\begin{array}{l}\text { Decompression sickness } \\
\text { (Reference: without) }\end{array}$ & 2.79 & 1.37 & 5.69 & $<0.01^{* *}$ & 3.83 & 1.60 & 9.16 & $<0.01^{* *}$ \\
$\begin{array}{l}\text { Gender (Reference: female) } \\
\begin{array}{l}\text { Age (years) (Reference: 20-44) } \\
45-64\end{array}\end{array}$ & 0.58 & 0.25 & 1.38 & 0.22 & 0.87 & 0.34 & 2.20 & 0.77 \\
$>65$ & 0.42 & 0.21 & 0.84 & $0.01^{*}$ & 0.40 & 0.19 & 0.82 & $0.01^{*}$ \\
HBO therapy & 0.64 & 0.31 & 1.34 & 0.24 & 0.67 & 0.30 & 1.48 & 0.32 \\
(Reference: without) & 1.98 & 0.61 & 6.42 & 0.26 & 0.76 & 0.17 & 3.31 & 0.71 \\
\hline
\end{tabular}

$\mathrm{HR}=$ hazard ratio; $\mathrm{CI}=$ confidence interval; Adjusted $\mathrm{HR}$ : Adjusted variables listed in the Table $1 ; \quad * \mathrm{P}<0.05,{ }^{*} * \mathrm{P}<0.01$ 
Table 5. Factors of subgroups of psychiatric disorders in the end of follow-up by using Cox regression

\begin{tabular}{|c|c|c|c|c|c|c|c|c|}
\hline $\begin{array}{l}\text { Decompression sickness } \\
\text { Psychiatric disorders }\end{array}$ & Event & $\begin{array}{l}\text { With } \\
\text { Rate } \\
\text { (per } 105 \text { PYs) }\end{array}$ & Event & $\begin{array}{l}\text { Without } \\
\text { Rate } \\
\text { (per 105 PYs) }\end{array}$ & Adjusted HR & $95 \% \mathrm{CI}$ & $95 \% \mathrm{CI}$ & $P$ \\
\hline Overall & 10 & $2,160.76$ & 35 & $1,604.16$ & 3.827 & 1.600 & 9.156 & 0.003 \\
\hline Depressive disorder & 2 & 432.15 & 11 & 504.16 & 0.417 & 0.040 & 4.348 & 0.465 \\
\hline Anxiety disorder & 1 & 216.08 & 3 & 137.50 & 4.452 & 0.057 & 6.238 & 0.498 \\
\hline Sleep disorder & 3 & 648.23 & 14 & 641.66 & 5.738 & 1.043 & 31.557 & 0.045 \\
\hline Stress-related disorders & 3 & 648.23 & 0 & 0.00 & - & - & - & - \\
\hline Adjustment disorders & 0 & 0.00 & 0 & 0.00 & - & - & - & - \\
\hline PTSD & 1 & 216.08 & 0 & 0.00 & - & - & - & - \\
\hline ASD & 1 & 216.08 & 0 & 0.00 & - & - & - & - \\
\hline Acute and reactive psychosis & 1 & 216.08 & 0 & 0.00 & - & - & - & - \\
\hline Delirium & 0 & 0.00 & 0 & 0.00 & - & - & - & - \\
\hline Dementia and other & 1 & 216.08 & 8 & 366.66 & 1.428 & 0.161 & 12.696 & 0.749 \\
\hline
\end{tabular}

PYs = Person-years; Adjusted HR = Adjusted Hazard ratio: Adjusted for the variables listed in Cox sheet; CI = confidence interval; PTSD: posttraumatic stress disorder; ASD = acute stress disorder

Table 6. Factors of risk of psychiatric disorders / sleep disorders among different type of decompression sickness by using Cox regression

\begin{tabular}{lccc}
\hline Decompression sickness (With vs. without) & Adjusted HR & $95 \%$ CI & $95 \%$ CI \\
\hline Psychiatric disorders & $3.83^{* *}$ & 1.600 & 9.160 \\
Type & $2.67^{* *}$ & 1.680 & 13.190 \\
Type-mild & $4.71^{*}$ & 1.620 & 11.400 \\
Type-severe & $5.98^{* *}$ & 1.750 & 8.710 \\
Sleep disorders & $5.74^{*}$ & 1.043 & 31.557 \\
Type & $4.13^{*}$ & 1.035 & 31.564 \\
Type-mild & $5.73^{*}$ & 1.001 & 30.298 \\
Type-severe & $5.86^{*}$ & 1.052 & 33.497 \\
\hline
\end{tabular}

Adjusted $\mathrm{HR}=$ Adjusted Hazard ratio: Adjusted for variables listed in Table 1; CI = confidence interval; $\mathrm{P}: * \mathrm{P}<0.05, * * \mathrm{P}<0.01$

disorders, were associated with no matter whether type I or type II DCS. The mean time from diagnosis of DCS to the first visit for psychiatric disorders was 994.41 $(\mathrm{SD}=594.75)$ days, and the psychiatric treatment duration in the DCS patients in the follow up period was $17.09(\mathrm{SD}=16.06)$ months.

\section{DISCUSSION}

In this nationwide population-based retrospective study, the principal finding is that the patients with DCS had an increased risk (HR $=3.83 ; 95 \%$ CI 1.60 to 9.16, $\mathrm{P}<0.01)$ for the development of psychiatric disorders within the follow-up period, as compared with an ageand sex-matched control group. In addition, patients with DCS who were male or older than 45 years, had a higher HR in comparison to the control group. Sleep disorders are associated with an adjusted HR of 5.74 (95\% $\mathrm{CI}=1.04$ to $31.56, \mathrm{P}<0.05)$. We have also found that the mean duration from diagnosis of DCS to the first visit for psychiatric disorders was 994.41 $(\mathrm{SD}=594.75)$ days, and the treatment of psychiatric disorders in the follow up period was. $17.09(\mathrm{SD}=16.06)$ months, respectively. In addition, the risk of psychiatric and sleep disorders increased with the severity of DCS.
Therefore, the psychiatric disorders after DCS were not just in an acute or transient course. This is the first nationwide, population-based, cohort study about the risk of psychiatric disorders in a DCS patient, to the best of our knowledge.

In this study, the treatment prevalence of psychiatric disorders in the control group was $5.7 \%$, which is similar to the previous studies using the NHIRD to investigate the risk of psychiatric disorders in some physical diseases, which ranged from $5-8 \%$, for examples, $5.6 \%$ of psychiatric disorders in the control group in a study for pelvic inflammatory disease (Shen et al. 2016), $4.42 \%$ in a study for primary Sjögren syndrome (Shen et al. 2015), 5.01\% in a study for ankylosing spondylitis (Shen et al. 2016), 7.5\% in a study for Guillain-Barre syndrome (Tzeng et al. 2017), or $8.77 \%$ in a study for patients who received weight control surgery (Chien et al. 2017), respectively. One previous study has reported that there were $19 \%$ of psychiatric difficulties in the group of diving accidents, which included DCS and other accidents in the diving, in comparison to control group of $5 \%$ of psychiatric difficulties, by scoring above the cut-off from the 28-item version of the General Health Questionnaire (GHQ) (McQueen et al. 1994). However, the present study focused on the percentage 
of psychiatric disorder in the DCS group, as $8.1 \%$. No comparable studies using the NHIRD were found, we thus tried to investigate on a similar topic, traumatic brain injury (TBI), while several studies about the association between TBI and psychiatric disorders found that there were 5.9\% bipolar disorders (Huang et al. 2018), 1.78\% substance-related disorders (Wu et al. 2016), or 1.41\%-2.97\% mood disorders (Chi et al. 2016, Tsai et al. 2014), and $28.34 \%$ insomnia (Chiu et al. 2015), in the patients of TBI. Since there were no previous studies about the prevalence of psychiatric disorders in Taiwan, a community survey for this topic is needed in the future. In addition, there were no stressrelated disorders, for example, PTSD, in the control group in this study. This seem to be extraordinary low, however, in one study using NHIRD for the study of psychiatric disorders in patients after occupational injury, the incidence of PTSD in the control group of any diseases instead of occupational injury was $0.03 \%$ (Chen et al. 2014), which is lower than the prevalence rates in Western countries (Javidi \& Yadollahie 2012, Lukaschek et al. 2013). This might be related to the underestimate or under-diagnosis of PTSD or other stress-related psychiatric disorders in Taiwan (Chen et al. 2017, Chien et al. 2017).

In this study, the people with DCS of age 45-64, with the reference of age 20-44, was associated with a lower risk of psychiatric disorders (adjusted $\mathrm{HR}=0.40$ (95\% CI: 0.19 to $0.82, \mathrm{p}=0.01)$ ). We hypothesize that diving is generally appropriate for younger individuals (Strauss et al. 2017), and older people might be more cautious in obeying both the diving and the decompression protocols. Therefore, the DCS could be less severe if it did occur, and thus be associated with a lower risk of psychiatric disorders in this age group.

Several previous reports found that DCS could make an impact on the patients' brains. Long-term neuropsychological changes in divers who had used compressed air were first described in 1966 (Rozsahegyi \& Roth 1966). Furthermore, divers with a history of DCS have an increased risk of neuropsychological symptoms (Bast-Pettersen et al. 2015, Trevett et al. 2010). Several studies had reported that long term memory impairment might be related to the cumulative diving exposure (Bast-Pettersen et al. 2015, Calder 1992, Edmonds \& Boughton, Hemelryck et al. 2014, Irgens et al. 2007, McQueen et al. 1994, Pourhashemi et al. 2016, Ross et al. 2007, Slosman et al. 2004, Sutherland et al. 1993, Taylor et al. 2006, Tetzlaff et al. 1999, Trevett et al. 2010, Vaernes et al. 1989, Williamson et al. 1987). However, the neurocognitive function in either the military or the highly professional divers, such as construction divers (Bast-Pettersen 1999), German Navy divers (Cordes et al. 2000), U.S. Navy saturation divers (Curley 1988), and elite apnea divers (Ridgway \& McFarland 2006), does not change. Depressive response, denial, and feelings of conflicts were also noted in the psychological responses in several patients with DCS (Hunt 1996). Neurological DCS, include visual, cognitive, motor, and sensory difficulties (Auten et al. 2010, Cianci \& Slade 2006, Wirjosemito et al. 1989). Although the residual symptoms were as low as 1.5-6.9\% (Wirjosemito et al. 1989), we speculate that these residual neurological difficulties, as the psychological impacts, might also contribute the risk of psychiatric disorders. The underlying mechanisms of the increased risk of psychiatric disorders in DCS patients remain unclear.

In addition, it is also worthwhile considering that some divers are different from the general population. Several studies have investigated the differences of personality traits between the divers and the general population (Bonnet et al. 2003, Harding \& Gee 2008, van Wijk 2017). Among the personality traits, the risktaking behaviors is associated with sensitivity to negative emotions, and there might be a link between the divers and the risk of psychiatric disorders, rather than simply DCS (Bonnet et al. 2003). Further research is therefore needed for examining the relationship between the divers' personality traits and the risk of DCS and psychiatric disorders, and the personality disorders in patients with DCS and psychiatric disorders by using NHIRD.

In our study, sleep disorders were significantly associated with DCS, in comparison to other psychiatric disorders. Previous studies had shown sleep disorders were one of the acute symptoms of neurological DCS and high-pressure neurological syndrome (Jain 1994). Several studies have reported the association between the TBI, white matter, and sleep (Fakhran et al. 2013). Although the microbubbles were mainly located in the cortex and subcortical white matter (Kohshi et al. 2014), which was not a major contributor to the circadian rhythm of sleep, the volume of cerebral lesions might be underestimated because of the low sensitivity of a brain MRI in divers (Gronning et al. 2005). However, this is the first study of sleep disorders as the delayed effects of DCS. Professional or career diving may involve shift work (Gamedze 2014, Hitchen 2013, Park et al. 1983), and shift work has pronounced negative effects on sleep and health (Akerstedt \& Wright 2009, Cheng et al. 2017), and we would recommend more researches that focus on the work-shift patterns and occupational stress, which might be related to sleep disorders, in the professional divers.

HBO therapy is widely used in the treatment of the neurological symptoms of DCS, but no previous literatures have studied the effects on the psychiatric disorders in the patients with DCS (Boussuges et al. 1996, Germonpre et al. 2016, Rios-Tejada et al. 1997, Sheffield \& Davis 1976, Wang et al. 2002). Therefore, we also investigate the previous researched on the TBI and the neuropsychiatric sequelae. Some pilot studies have tried to treat psychiatric disorders. For example, in several previous studies, HBO therapy was associated with improvements in the TBI-associated cognitive 
deficits, PTSD, and post-concussive symptoms (BoussiGross et al. 2013, Eve et al. 2016, Hadanny et al. 2018, Harch et al. 2012). However, one randomized clinical control trials found that the observed improvements in the post-concussive symptoms were not HBO mediated but may reflect nonspecific improvements related to placebo effects (Miller et al. 2015). In the present study, HBO therapy was not associated with a decreased risk of the psychiatric disorders, and a further randomized control study is needed to evaluate whether HBO therapy would be effective in the prevention of psychiatric disorders in the DCS patients.

\section{Limitations}

Several limitations of the study must be taken into consideration. First, patients with DCS in Taiwan are mostly males, and the generalization of this finding to female patients with DCS is limited. Second, the time and depths of diving, which is crucial in microbubble exposure is not clear in such a dataset. Third, DCS can be regarded as a traumatic event, however, the records of traumatic events other than the DCS were not available in the NHIRD, either in the DCS or non-DCS group. We could not analyze the traumatic events other than the DCS in the subjects in this medical claims dataset-based study. Fourth, we have only enrolled individuals aged $>20$ in this study, and the results didn't include the influences of the DCS on the teenage groups. Fifth, the end time of inclusion period overlaps with the end of follow-up period. However, the difference of cumulative incidence of psychiatric disorders reached statistical significance between DCS and non-DCS groups since the sixth year of follow up (Table 3), which seems to be reasonable duration for the patients with DCS to the development of psychiatric disorders. Sixth, in this study, only ten patients with DCS developed psychiatric disorders, and this small number could limit the ability in generalizing the findings, and this could be the largest limitation in the present study. Lastly, even though we have included DM, hypertension and hyperlipidemia as the comorbidity, the body mass index (BMI) and serum cholesterol levels, which are risk factors for the development of DCS (Jain 2016), are not included in the claims dataset. A future study for the recruitment of more DCS patients with detailed descriptions is therefore warranted.

\section{CONCLUSION}

Patients who have suffered from DCS are associated with an increased risk of psychiatric disorders (adjusted HR: 3.83 ; 95\% CI 1.60 to 9.16 ; $\mathrm{P}<0.01$ ), especially sleep disorders. This finding should be considered as a reminder to the clinicians, that a regular psychiatric follow-up might well be needed for these patients.

\section{Acknowledgements: None.}

Conflict of interest: None to declare.

\section{Contribution of individual authors:}

Wei-Shih Tseng: concept and design of the article; literature searches; data collection, interpretation, and analysis, writing the manuscript; approval of the final version;

Wu-Chien Chien \& Chi-Hsiang Chung: statistical analysis, data interpretation, comments on the draft paper; approval of the final version;

Yu-Ching Chou: data interpretation, comments on the draft paper; approval of the final version;

Nian-Sheng Tzeng: concept and design of the article; literature searches; data collection, interpretation, and analysis, statistical analysis, approval of the final version.

\section{References}

1. Akerstedt $T$ \& Wright KP: Sleep Loss and Fatigue in Shift Work and Shift Work Disorder. Sleep Med Clin 2009; 4:257-71

2. Auten JD, Kuhne MA, Walker HM \& Porter HO: Neurologic decompression sickness following cabin pressure fluctuations at high altitude. Aviat Space Environ Med 2010; 81:427-30

3. Bast-Pettersen R: Long-term neuropsychological effects in non-saturation construction divers. Aviat Space Environ Med 1999; 70:51-7

4. Bast-Pettersen R, Skare O, Nordby KC \& Skogstad M: A twelve-year longitudinal study of neuropsychological function in non-saturation professional divers. Int Arch Occup Environ Health 2015; 88:669-82

5. Bonnet A, Pedinielli JL, Romain F \& Rouan G: Subjective well-being and self-regulation in risk taking behaviors. The case of scuba-diving. Encephale 2003; 29:488-97

6. Boussi-Gross R, Golan H, Fishlev G, Bechor Y, Volkov O, Bergan J, et al.: Hyperbaric oxygen therapy can improve post concussion syndrome years after mild traumatic brain injury randomized prospective trial. PLoS One 2013; 8:e79995

7. Boussuges A, Thirion X, Blanc P, Molenat F \& Sainty JM: Neurologic decompression illness: a gravity score. Undersea Hyperb Med 1996; 23:151-5

8. Calder I: Does diving damage your brain? Occup Med (Lond) 1992; 42:213-4

9. Chen MH, Li CT, Lin WC, Wei HT, Chang WH, Chen TJ, et al.: A predisposition for allergies predicts subsequent hypertension, dyslipidemia, and diabetes mellitus among patients with schizophrenia or bipolar disorder: a nationwide longitudinal study. Schizophr Res 2014; 159:171-5

10. Chen YC, Yeh HY, Wu JC, Haschler I, Chen TJ \& Wetter T: Taiwan's National Health Insurance Research Database: administrative health care database as study object in bibliometrics. Scientometrics 2010; 86:365-80

11. Chen YH, Wei HT, Bai YM, Hsu JW, Huang KL, Su TP, et al.: Risk of Epilepsy in Individuals With Posttraumatic Stress Disorder: A Nationwide Longitudinal Study. Psychosom Med 2017; 79:664-9 
12. Cheng P, Tallent G, Bender TJ, Tran KM \& Drake CL: Shift Work and Cognitive Flexibility: Decomposing Task Performance. J Biol Rhythms 2017; 32:143-53

13. Chi YC, Wu HL, Chu CP, Huang MC, Lee PC \& Chen YY: Traumatic brain injury and affective disorder: A nationwide cohort study in Taiwan, 2000-2010. J Affect Disord 2016; 191:56-61

14. Chien WC, Chung $\mathrm{CH}$, Lin FH, Chang HA, Kao YC \& Tzeng NS: Is weight control surgery associated with increased risk of newly onset psychiatric disorders? A population-based, matched cohort study in Taiwan. J Med Sci 2017; 37:137-49

15. Chiu HY, Lin EY, Wei L, Lin JH, Lee HC, Fan YC, et al.: Hypnotics use but not insomnia increased the risk of dementia in traumatic brain injury patients. Eur Neuropsychopharmacol 2015; 25:2271-7

16. Cianci P \& Slade JB, Jr.: Delayed treatment of decompression sickness with short, no-air-break tables: review of 140 cases. Aviat Space Environ Med 2006; 77:1003-8

17. Connolly DM \& Lee VM: Odds Ratio Meta-Analysis and Increased Prevalence of White Matter Injury in Healthy Divers. Aerosp Med Hum Perform 2015; 86:928-35

18. Cordes P, Keil R, Bartsch T, Tetzlaff K, Reuter M, Hutzelmann A, et al.: Neurologic outcome of controlled compressed-air diving. Neurology 2000; 55:1743-5

19. Curley MD: U.S. Navy saturation diving and diver neuropsychologic status. Undersea Biomed Res 1988; 15:39-50

20. Edmonds C, Bennett M, Lippmann J \& Mitchell S. Diving and Subaquatic Medicine. Fifth Edition. London, New York: CRC Press; 2015

21. Edmonds $C$ \& Boughton J: Intellectual deterioration with excessive diving (punch drunk divers). Undersea Biomed Res 1985; 12:321-6

22. Eve DJ, Steele $M R$, Sanberg $P R$ \& Borlongan $C V$ : Hyperbaric oxygen therapy as a potential treatment for post-traumatic stress disorder associated with traumatic brain injury. Neuropsychiatr Dis Treat 2016; 12:2689705

23. Fakhran S, Yaeger $K$ \& Alhilali L: Symptomatic white matter changes in mild traumatic brain injury resemble pathologic features of early Alzheimer dementia. Radiology 2013; 269:249-57

24. Francis T, James $R \&$ Mitchell Simon J. Manifestations of Decompression Disorders. In: Brubakk A \& Neuman T, editors. Bennett and Elliott's physiology and medicine of diving 5th Revised Edition. United States: Saunders, 2003; p. 578-99

25. Gamedze L. A day in the life of an offshore diver part 1. Divers Institute of Technology, 2014

26. Germonpre P, Levie P, Dehalleux C \& Caers D: ENT indications for Hyperbaric Oxygen Therapy. B-ENT 2016; Suppl 26:87-106

27. Gronning M, Risberg J, Skeidsvoll H, Moen G, Aanderud $L$, Troland K, et al.: Electroencephalography and magnetic resonance imaging in neurological decompression sickness. Undersea Hyperb Med 2005; 32:397-402

28. Hadanny A, Abbott S, Suzin G, Bechor Y \& Efrati S: Effect of hyperbaric oxygen therapy on chronic neurocognitive deficits of post-traumatic brain injury patients: retrospective analysis. BMJ Open 2018; 8:e023387

29. Harch PG, Andrews SR, Fogarty EF, Amen D, Pezzullo JC, Lucarini $J$, et al.: A phase I study of low-pressure hyperbaric oxygen therapy for blast-induced post-concussion syndrome and post-traumatic stress disorder. J Neurotrauma 2012; 29:168-85

30. Harding S \& Gee P: Personality as a predisposing factor for DCI: a pilot study. Diving Hyperb Med 2008; 38:134-8

31. Hemelryck W, Germonpre P, Papadopoulou V, Rozloznik $M$ \& Balestra C: Long term effects of recreational SCUBA diving on higher cognitive function. Scand $J$ Med Sci Sports 2014; 24:928-34

32. Hitchen P. Life under pressure: a day in the life of a sat diver. The Underwater Centre, 2013

33. Ho Chan WS: Taiwan's healthcare report 2010. EPMA J 2010; 1:563-85

34. Hopkins RO \& Weaver LK: Acute psychosis associated with diving. Undersea Hyperb Med 2001; 28:145-8

35. Howle LE, Weber PW, Hada EA, Vann RD \& Denoble PJ: The probability and severity of decompression sickness. PLoS One 2017; 12:e0172665

36. Huang MF, Su CH, Tu HP, Liu TL, Lin CL, Chen CS, et al.: Association between bipolar disorder and subsequent traumatic brain injury in patients who received inpatient treatment. Psychiatry Res 2018; 261:517-21

37. Huchim-Lara $O$, Chin $W$, Salas $S$, Rivera-Canul $N$, Cordero-Romero S, Tec J, et al.: Decompression sickness among diving fishermen in Mexico: observational retrospective analysis of DCS in three sea cucumber fishing seasons. Undersea Hyperb Med 2017; 44:149-56

38. Hunt JC: Psychological aspects of scuba diving injuries: Suggestions for short-term treatment from a psychodynamic perspective. J Clin Psychol Med Settings 1996; 3:253-71

39. Irgens A, Gronning M, Troland K, Sundal E, Nyland H \& Thorsen E: Reduced health-related quality of life in former North Sea divers is associated with decompression sickness. Occup Med (Lond) 2007; 57:349-54

40. Jain KK: High-pressure neurological syndrome (HPNS). Acta Neurol Scand 1994; 90:45-50

41. Jain KK. Textbook of Hyperbaric Medicine. Sixth Edition. Switzerland: Springer International Publishing AG; 2016

42. Javidi H \& Yadollahie M: Post-traumatic Stress Disorder. Int J Occup Environ Med 2012; 3:2-9

43. Kohshi K, Tamaki H, Lemaitre F, Okudera T, Ishitake T \& Denoble PJ: Brain damage in commercial breath-hold divers. PLoS One 2014; 9:e105006

44. Lukaschek K, Kruse J, Emeny RT, Lacruz ME, von Eisenhart Rothe A \& Ladwig KH: Lifetime traumatic experiences and their impact on PTSD: a general population study. Soc Psychiatry Psychiatr Epidemiol 2013; 48:525-32

45. McQueen D, Kent G \& Murrison A: Self-reported longterm effects of diving and decompression illness in recreational scuba divers. Br J Sports Med. 1994; 28:101-4

46. Miller RS, Weaver LK, Bahraini N, Churchill S, Price RC, Skiba $V$, et al.: Effects of hyperbaric oxygen on symptoms and quality of life among service members with persistent postconcussion symptoms: a randomized clinical trial. JAMA Intern Med 2015; 175:43-52

47. Morgan WP: Anxiety and panic in recreational scuba divers. Sports Med 1995; 20:398-421

48. Nicolas M, Thullier-Lestienne F, Bouquet C, Gardette B, Gortan C, Richalet JP, et al.: A study of mood changes and personality during a 31-day period of chronic hypoxia in a hypobaric chamber (Everest-Comex 97). Psychol Rep 2000; 86:119-26 
49. Park YS, Rahn H, Lee IS, Lee SI, Kang DH, Hong SY, et al.: Patterns of wet suit diving in Korean women breathhold divers. Undersea Biomed Res 1983; 10:203-15

50. Pourhashemi SF, Sahraei H, Meftahi GH, Hatef B \& Gholipour B: The Effect of 20 Minutes Scuba Diving on Cognitive Function of Professional Scuba Divers. Asian J Sports Med 2016; 7:e38633

51. Ridgway L \& McFarland K: Apnea diving: long-term neurocognitive sequelae of repeated hypoxemia. Clin Neuropsychol 2006; 20:160-76

52. Rios-Tejada F, Azofra-Garcia J, Valle-Garrido J \& Pujante Escudero A: Neurological manifestation of arterial gas embolism following standard altitude chamber flight: a case report. Aviat Space Environ Med 1997; 68:1025-8

53. Ross JA, Macdiarmid JI, Osman LM, Watt SJ, Godden DJ \& Lawson A: Health status of professional divers and offshore oil industry workers. Occup Med (Lond) 2007; 57:254-61

54. Rozsahegyi I \& Roth B: Participation of the central nervous system in decompression. Ind Med Surg 1966; 35:101-10

55. Sheffield PJ \& Davis JC: Application of hyperbaric oxygen therapy in a case of prolonged cerebral hypoxia following rapid decompression. Aviat Space Environ Med 1976; 47:759-62

56. Shen CC, Hu LY, Yang AC, Kuo BI, Chiang YY \& Tsai SJ: Risk of Psychiatric Disorders following Ankylosing Spondylitis: A Nationwide Population-based Retrospective Cohort Study. J Rheumatol 2016a; 43:625-31

57. Shen CC, Yang AC, Hung JH, Hu LY, Chiang YY \& Tsai SJ: Risk of psychiatric disorders following pelvic inflammatory disease: a nationwide population-based retrospective cohort study. J Psychosom Obstet Gynaecol 2016b; 37:6-11

58. Shen CC, Yang AC, Kuo BI \& Tsai SJ: Risk of Psychiatric Disorders Following Primary Sjogren Syndrome: A Nationwide Population-based Retrospective Cohort Study. J Rheumatol 2015; 42:1203-8

59. Slosman DO, De Ribaupierre S, Chicherio C, Ludwig C, Montandon ML, Allaoua $M$, et al.: Negative neurofunctional effects of frequency, depth and environment in recreational scuba diving: the Geneva "memory dive" study. Br J Sports Med 2004; 38:108-14

60. Strauss MB, Busch JA \& Miller SS: Scuba in older-aged divers. Undersea Hyperb Med 2017; 44:45-55

61. Sutherland A, Veale A \& Gorman D: Neuropsychological problems in 25 recreational divers one year after treatment for decompression illness SPUMS J 1993; 23:7-11
62. Taylor CL, Macdiarmid JI, Ross JA, Osman LM, Watt SJ, Adie $W$, et al.: Objective neuropsychological test performance of professional divers reporting a subjective complaint of "forgetfulness or loss of concentration". Scand J Work Environ Health 2006; 32:310-7

63. Tetzlaff K, Friege L, Hutzelmann A, Reuter M, Holl D \& Leplow B: Magnetic resonance signal abnormalities and neuropsychological deficits in elderly compressed-air divers. Eur Neurol 1999; 42:194-9

64. Trevett A, Peck D \& Forbes $R$ : The psychological impact of accidents on recreational divers: a prospective study. $J$ Psychosom Res 2010; 68:263-8

65. Tsai MC, Tsai KJ, Wang HK, Sung PS, Wu MH, Hung $K W$, et al.: Mood disorders after traumatic brain injury in adolescents and young adults: a nationwide populationbased cohort study. J Pediatr 2014; 164:136-41.e1

66. Tzeng NS, Chang HA, Chung CH, Lin FH, Yeh CB, Huang SY, et al.: Risk of psychiatric disorders in Guillain-Barre syndrome: A nationwide, population-based, cohort study. J Neurol Sci 2017; 381:88-94

67. Vaernes RJ, Klove $H$ \& Ellertsen B: Neuropsychologic effects of saturation diving. Undersea Biomed Res 1989; 16:233-51

68. van Wijk CH: Personality and behavioural outcomes in diving: current status and recommendations for future research. Diving Hyperb Med 2017; 47:248-52

69. Vgontzas AN, Zoumakis M, Bixler EO, Lin HM, Prolo P, Vela-Bueno A, et al.: Impaired nighttime sleep in healthy old versus young adults is associated with elevated plasma interleukin-6 and cortisol levels: physiologic and therapeutic implications. J Clin Endocrinol Metab 2003; 88:2087-95

70. Wang J, Corson K, Minky K \& Mader J: Diver with acute abdominal pain, right leg paresthesias and weakness: a case report. Undersea Hyperb Med. 2002; 29:242-6

71. Williamson AM, Clarke B \& Edmonds C: Neurobehavioural effects of professional abalone diving. $\mathrm{Br} J$ Ind Med 1987; 44:459-66

72. Wirjosemito SA, Touhey JE \& Workman WT: Type II altitude decompression sickness (DCS): U.S. Air Force experience with 133 cases. Aviat Space Environ Med 1989; 60:256-62

73. Wu CH, Tsai TH, Su YF, Zhang ZH, Liu W, Wu MK, et al.: Traumatic Brain Injury and Substance Related Disorder: A 10-Year Nationwide Cohort Study in Taiwan. Neural Plast 2016; 2016:8030676

\section{Correspondence:}

Nian-Sheng Tzeng, MD, Assistant Professor and Attending Psychiatrist

Director of Joint Program of Geriatric Psychiatry and Psychosomatic Medicine, Department of Psychiatry

Tri-Service General Hospital, National Defense Medical Center

325, Chung-Gung Rd, Sec 2, Nei-Hu District 114, Tapei, Taiwan, ROC

E-mail:pierrens@mail.ndmctsgh.edu.tw 